\title{
Judging Credibility of a Road Traffic Accident Claimant
}

\author{
Koch $\mathrm{H}^{* 1}$, Akehurst $\mathrm{L}^{2}$ and Easton $\mathrm{S}^{3}$ \\ ${ }^{1}$ Chartered Psychologist and Director, Hugh Koch Associates, Cheltenham, UK \\ ${ }^{2}$ Deputy Director, International Centre for Research in Forensic Psychology and Senior Lecturer - Department of \\ Psychology, University of Portsmouth, UK \\ ${ }^{3}$ Chartered Psychologist, Department of Psychology, University of Portsmouth, UK
}

${ }^{*}$ Corresponding author: Koch H, Hugh Koch Associates, Festival House, Jessop Avenue, Cheltenham GL50 3SH, UK, Tel: 0044-1242-263715, E-mail: Hugh@hughkochassociates.co.uk

Citation: Koch H, Akehurst L, Easton S (2017) Judging Credibility of a Road Traffic Accident Claimant. J Case Rep Stud 5(2): 203. doi: 10.15744/2348-9820.5.203

Received Date: March 14, 2017 Accepted Date: April 25, 2017 Published Date: April 27, 2017

\begin{abstract}
The 'holy grail' of being able to assess reliability and truthfulness is investigated one step further via this case study utilising a credibility checklist with a road traffic accident claimant. The possibility of operationalising unreliability in a numerical, or at least, an informed narrative way is explored in this innovative study.
\end{abstract}

Keywords: Road Traffic; Accident

\section{Introduction}

Civil claims are complex. In 2014, the association of British Insurers found that $6 \%$ claim costs were represented by fraud and $5-10 \%$ of claims were not genuine [1]. The court requires appropriate evidence from a variety of sources: claimant self-report, medical notes (GP and Hospital), occupational records and expert clinical and legal judgment. However, the starting point is the claimant providing their own information about the circumstances and after effects of one particular 'index' event. An expert witness called upon to interview the claimant and formulate an opinion is faced with assessing claimant credibility and reliability.

There are many potential areas of unreliability in assessing personal injuries, both physical and psychological and these impinge on both clinical and medico-legal processes [2-4]. The fundamental psychosocial basis for interviewing is the claimant's communication style consisting as it does of verbal and non-verbal components. It is this area that has resulted in a significant psychological literature on 'unreliability, lying and malingering' as it relates to the evaluation of an individual's presentation at interview and can inform experts as they consider the truthfulness and validity of a claimant's reported experiences [5-8]. The 'holy grail' of deception detection is to try to operationalize many behavioural cues into an assessment process to judge credibility in a medico-legal setting [7-10].

\section{Development of a Credibility Checklist}

The Portsmouth group of researchers [10-12] collated a selection of verbal and non-verbal cues indicative of potential 'lying/ malingering' or 'truthfulness', based on available literature and interviewing techniques. The resulting pilot checklist tool was evaluated in an experimental way in terms of its usefulness in discriminating truthful interviewees from those who were malingering [10]. Interviewees using this checklist achieved $75 \%$ correct classifications of truthful interviewers and $66 \%$ correct classification of those who were exaggerating symptoms. Interviewers who were not given the checklist did not classify their interviewees at a level significant better than chance (50\%). This study indicated that further exploration of the use of a checklist by interviewers in a medico-legal setting was required with further refinement of item scoring, inter-rater reliability and test/ re-test reliability. A significant next step would be how the checklist and its use could offer the courts some reassurance that the expert could operationalize his/her own 'clinical judgement' of claimant reliability. This might be achieved by use of a structured aide memoire based on research into cues to truthfulness or deception. Concern was, however, raised by these researchers on the basis that the device developed was not intended to serve as a formal psychometric test. With these aspirations and concerns, the current authors set out to achieve the following: -

1. To adapt the credibility checklist for use with road traffic claimants

2. To use the checklist as part of a single case study

3. To establish a protocol for a wider pilot study 


\section{Background to Case}

The following anonymised case was utilized in this study: -

Mr Jones, 45, was a car driver involved in a serious road traffic collision with an oncoming vehicle.

He suffered physical injuries including neck, shoulder and back injuries with a diagnosis of whiplash disorder.

He also suffered psychological injuries including stress, shock, travel anxiety and mood disturbance. He had three months off work.

\section{Adaptation of Credibility Checklist}

The original checklist (10) was amended in two ways:

\section{Item alteration}

Each item had the experimental 'cold plunge' reference altered to 'road traffic accident'. For example, 'does the individual when talking about the cold plunge was altered to 'does the individual when talking about the RTA'.

\section{Numerical scale alteration}

Each item had the experimental 'cold plunge' reference altered to 'road traffic accident'. For example, 'does the individual when talking about the cold plunge was altered to 'does the individual when talking about the RTA'.

The 5 point scale was applied so that any item which purported to measure unreliability could achieve a maximum score of 4 , whereas an item purporting to measure reliability would prompt a score of 0 (when found to apply 'always'). This meant that the cumulative score (the total score for all 28 items) would indicate how unreliable the claimant was assessed as being (maximum score 112 , minimum score 0 ).

\section{Use of the checklist to evaluate one claimant}

Interview information about one claimant by the first author was utilised to rate the person on the 28 items. An overall score for unreliability was computed. Feedback was provided concerning the utility and application of the items and the process of making such ratings. Comment was also made on potential ways of using the results to give a coherent opinion to the court on a claimant's reliability.

\section{Establish a protocol for a wider pilot study}

This initial pilot study was undertaken on one case only. At the end of the case study, we have established a 'next stage' protocol for carrying out a wider pilot study to further refine the use of the checklist by experts in civil cases.

\section{Scoring the credibility 'in vivo' of Mr. Jones}

In this case study, the expert (first author) looked for examples of each of the 28 characteristics during the 45-minute interview, noting these down on the checklist proforma (in a $3^{\text {rd }}$ column). If more than one example occurred, this was noted by an asterisk. Due to the exploratory nature of this single case study pilot, we did not control for social or demographic variables, claim size, severity of mechanical physical or psychological damage. This was a standard 'fast track' case indicative of mild to moderate damage. An illustration of this is shown in Figure 1 below.

\begin{tabular}{|c|c|c|c|c|c|}
\hline Item & \multicolumn{4}{|c|}{$\begin{array}{l}\text { Score } \\
\text { Never Always }\end{array}$} & Example \\
\hline $\begin{array}{l}\text { 2. Does the individual show } \\
\text { long latency periods, that is } \\
\text { the time between the end of a } \\
\text { question and the beginning of } \\
\text { an answer? }\end{array}$ & 0 & 1 & 2 & 4 & $\begin{array}{l}\text { Appeared to be thinking } \\
\text { about whether he had } \\
\text { nightmares or not (i.e. did } \\
\text { not give quick answers) }\end{array}$ \\
\hline $\begin{array}{l}\text { 12. Does the individual, when } \\
\text { talking about the RTA and } \\
\text { subsequent experience, show } \\
\text { self-deprecation (i.e. put him } \\
\text { or herself down)? }\end{array}$ & 4 & 3 & 2 & 0 & $\begin{array}{l}\text { Said he felt 'weak' and } \\
\text { 'stupid' reacting as he did. }\end{array}$ \\
\hline $\begin{array}{l}\text { 20. Is the individual falsely } \\
\text { ascribing real symptoms to the } \\
\text { RTA (e.g. had a bad back } \\
\text { anyway and now blaming the } \\
\text { RTA)? }\end{array}$ & 0 & 1 & 2 & 4 & $\begin{array}{l}\text { Multisite pain described } \\
\text { which had not been } \\
\text { mentioned to previous } \\
\text { orthopaedic surgeons. }\end{array}$ \\
\hline
\end{tabular}

Figure 1: Illustration of mild to moderate damage 
In the above extract from the completed checklist, it is evident that two items (items 2 and 20) indicated unreliability, whereas one item (item 12) indicated reliability.

At the end of the interview, the expert reviewed his notes and recall of the interview, and went through all 28 items allotting a score on each rating scale. When there was no overt evidence for rating any particular characteristic, then a value reflecting 'never' was used. Inter-rate reliability testing was not undertaken due to the exploratory nature of the study.

Finally, once all characteristics had been scored, a cumulative 'unreliability' score was computed. The range, as previously stated was $0-112$. Mr Jones scored 28.

\section{Interpreting this score}

At present, it would appear logical that an overall cumulative score could place an individual in one of three reliability groups:

1. Very Reliable- possible score 0 - 56 (approx.)

2. Very Unreliable - possible score $84-112$ (approx.)

3. Mixed Reliability - possible score - $56-84$ (approx.)

Using this classification, Mr Jones fell into the 'very reliable' group.

Whilst this crude interpretative approach serves for the current illustration, a larger sample would be required to refine and define any such use of the scores to reflect degree of reliability/unreliability.

\section{Communicating this interpretation to the 'Judge'}

One outcome of an expert's consideration of a claimant's reliability is that he/she may need to communicate his/her findings to a lawyer, barrister or judge. This remains a complex communication. However, the Credibility Checklist approach helps the expert frame a response in a logical way as follows, using the case of Mr. Jones : -

Mr. Jones was assessed during a lengthy, comprehensive interview on variables which are thought to contribute to a finding of reliability or unreliability. These included verbal, non-verbal and content characteristics.

Mr Jones scored 28: Given the range of possible scores is $0-112$, his score places him in the category of 'very reliable'.

Any assessment of credibility is beset with problems of reliability and adverse consequences. The risk of adverse outcome of a false positive or false negative in any opinion needs to be considered. However, in this field of credibility, there are currently very few explicit ways to advise the court, in any substantive way, as to a claimant's veracity. We believe that this approach is the beginning of a more reliable, valid and comprehensive tool which can be used.

\section{Confounding Variables and Other Issues}

Other variables which need to be taken into account when interpreting individual items scores include claimant mood and/or anxiety and severity of overall symptomatology i.e. a claimant who is depressed or highly anxious may come across as having higher scores (reflecting unreliability). Equally, a claimant with mild symptomatology, may also have a higher unreliability score which is actually reflecting a lack of significant stress or traumatic experience.

Other issues needing consideration in future field work include time taken to complete the checklist, need for single or multiple examples on which to score any one item, and the perceptions of legal professionals of the rationale and conclusions given by the expert. In addition the inter-rater reliability of different experts interviewing the same claimant would need to be taken into account.

\section{Discussion and Conclusion}

This initial case study has illustrated how a modified Credibility Checklist can be used to a) assess the reliability of a road traffic accident claimant, b) arrive at a single score of unreliability, c) interpret this score and d) communicate the finding to legal professionals.

A recent study has provided support for the Credibility Checklist, and indicates that reduction in items detracts from its reliability [10]. Further field work is necessary to reinforce the utility and interpretation of this method and scoring. Reducing fraud in this area of civil compensation is crucial [12] and has attracted significant interest in the legal press in the UK [11]. Credibility assessment has a key role to play in this area of deception detection [15] using this meta-analysis approach.

\section{Appendix I}

\section{References}

1. Association of British Insurers (2015) You couldn't make it up. Report. 13.07.15.

2. Sooniste T, Goonbag PA, Stromwall LA, Vriz A (2016) Discriminating between true and false intent among small cells of suspects. Legal Criminol Psychol 21: 344-57. 
3. Koch H, Elson P (2016) Areas of medico-legal unreliability in personal injury cases. Mathews J Cas Rep 2: 0024.

4. Koch H (2016) Medico-legal Case Commentary: Interface between clinical opinion and legal case reporting in personal injury litigation. Mathews J Cas Rep 1: 005.

5. Vrij A (2008) Detecting lies and Deception: Pitfalls and Opportunities (2 $2^{\text {nd }}$ Edn) Wiley, UK.

6. Easton S (2012) Assessing malingering, lying and deception for reports. Clinical Psychology Forum 229: 6-10.

7. Easton S, Akehurst L (2011) Tools for the detection of lying and malingering in the medico-legal interview setting. Med Leg J 79: 103-8.

8. Vrij A, Easton S (2002) Fact or Fiction? Verbal and behavioural cues to detect deception. Med Leg J 70: 29-37.

9. Koch H, Court K, Bates S (2016) Medico-legal Implications of Assessing Unreliability in Civil Compensation Cases: A Case Study Reflecting Potential Unreliability. SAJ Case Reports 4: 106.

10. Akehurst L, Easton S, Fuller E, Drane G, Kuzmin K, et al. (2017) An evaluation of a new tool to aid judgements of credibility in the medico-legal setting. Legal Criminol Psychol 22: 22-46.

11. Easton S, Akehurst L, Turtle S, Satchell L (2015) An evaluation of an abbreviated version of a checklist to aid judgements of credibility in the medico-legal setting. Open Acc J Foren Psychol 9: 1-18.

12. Koch H (2016) Legal Mind: Contemporary Issues in Psychological Injury and Law, Expert Witness Publications, Manchester, USA.

13. Koch H (2017) In: Modern Claims Magazine, Boxing cleverly to reduce fraud: An expert witness view, January 2017.

14. Vrij A, Fisher RP, Blank H (2015) A Cognitive Approach to Lie Detection: a Meta-Analysis. Legal Criminol Psychol 22 : 1-21.

15. Vrij A (2014) Interviewing to detect deception. European Psychologist 19: 184-95.

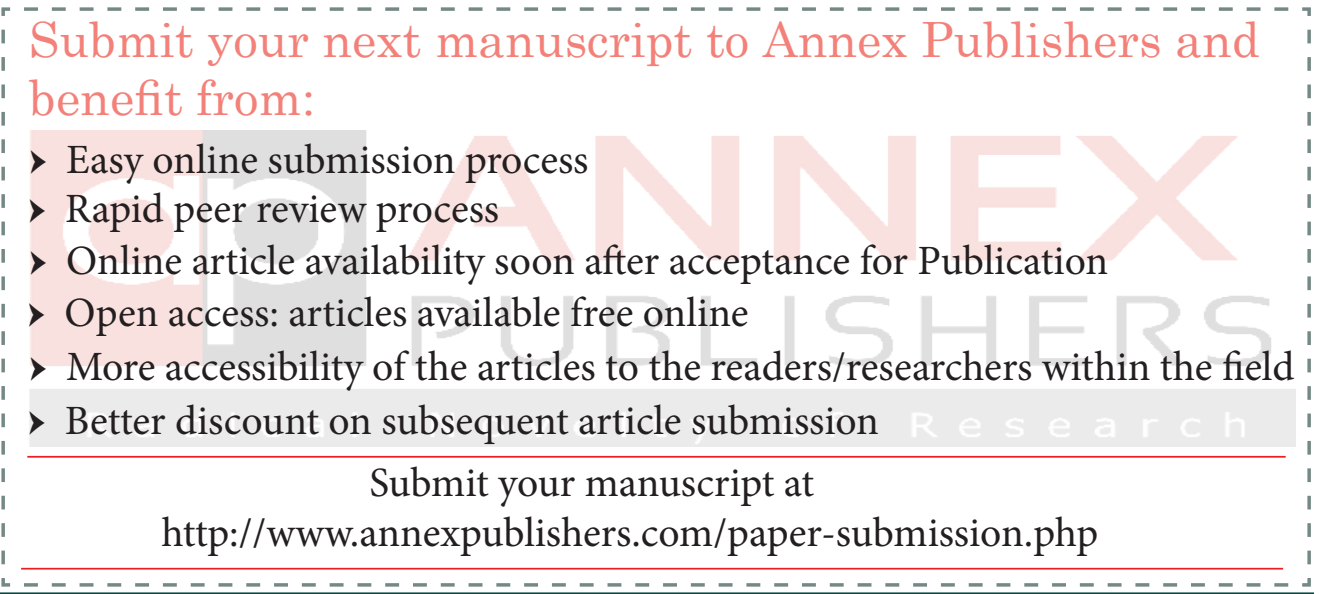

